Ben Phillips ～ORCID iD: 0000-0003-2580-2336

22 May 2020

Corresponding author:

Michael Kearney,

School of BioSciences, University of Melbourne, Victoria 3010,

Australia.

$+61383444864$

m.kearney@unimelb.edu.au

RH: Saleeba et al. • Biophysical Models and Survey Efficiency

\title{
Using Biophysical Models to Improve Survey Efficiency for Cryptic Ectotherms
}

KATE SALEEBA, School of BioSciences, University of Melbourne, Victoria 3010, Australia

BEN L. PHILLIPS, School of BioSciences, University of Melbourne, Victoria 3010, Australia

MEGAN O’SHEA, Institute of Sustainable Industries \& Liveable Cities, Victoria University, Victoria 3011, Australia

MICHAEL R. KEARNEY, ${ }^{1}$ School of BioSciences, University of Melbourne, Victoria 3010, Australia

${ }^{1}$ Email: m.kearney@unimelb.edu.au

This is the author manuscript accepted for publication and undergone full peer review but has not been through the copyediting, typesetting, pagination and proofreading process, which may lead to differences between this version and the Version of Record. Please cite this article as doi: 10.1002/jwmg.21890.

This article is protected by copyright. All rights reserved. 
Saleeba et al. • Biophysical Models and Survey

Efficiency

ABSTRACT Inefficiencies in monitoring programs waste resources. Ideally, we would predict when and where target species are most detectable and place our effort accordingly. Statistical models can generate predictor functions relating survey conditions to detectability but are phenomenological; they do not incorporate biological constraints and so using them to predict into unsampled time and space is risky. Biophysical ecology allows us to place constraints on detection by identifying abiotic conditions in which the target species cannot be present. We show how such constraint can be incorporated into standard detection models. We use the striped legless lizard (Delma impar), a threatened cryptic species, in southeastern Australia, as a case study, using fortnightly monitoring data collected between June 2016 to May 2017. These lizards are monitored by searching under tiles placed in arrays; we used a biophysical model to simulate the thermal microclimate under tiles and combined this with the striped legless lizard's thermal physiology to predict when tiles could be used. When compared against a large monitoring dataset, lizards were rarely observed at times the model predicted they should not be present, but the model also overpredicted presences. A statistical occupancy model showed that much of this overprediction is explained by a generally low detection probability, and a seasonal trend in detection beyond that captured in the biophysical model. We then replaced the temperature covariates of detection in the statistical model with our biophysical prediction (a categorical variable). The resulting model explained almost the same amount of variance in detections as the original model but using a single variable that captured biological constraints. The biophysical model allowed us to place mechanistic constraints on detection, but it still needed to be informed by observed 
Saleeba et al. • Biophysical Models and Survey

Efficiency

aspects of the species' behavior that were not influenced by temperature. Hybrid statistical-biophysical models such as ours offer a powerful tool for forecasting optimal survey conditions for a wide array of species.

KEY WORDS biophysical model, detection, ectotherm, NicheMapR, survey efficiency, thermal physiology.

Monitoring programs must be optimized to maximize information for resources spent (Michael et al. 2012, McGrath et al. 2015) and effort has been put into improving survey efficiency. We can optimize survey timing and use new technology (Gompper et al. 2006, Barr and Wilson 2015) to maximize detections per effort. To this end, weather can play an important role. Animals adjust their behavior to the weather and so weather changes their detectability. This is particularly true for ectotherms (Huey et al. 1989, Tracy et al. 2007, Downs et al. 2008, Hodapp et al. 2009). The challenge, then, is to understand the effect of weather on detection, and to be able to forecast quantified detection probabilities.

This challenge can be tackled with 2 different approaches: statistical and mechanistic. Statistical approaches infer how detection changes with environmental variables directly from the empirical observation records for a species (Kearney et al. 2010, Mathewson et al. 2017). Although these models provide a quantification of how different factors affect detection, they are risky for forecasting because observed relationships between environment and detection are restricted to the times and places where the data come from. Applying the model outside of this sample space is risky because no mechanistic constraints exist in these models (Kearney and Porter 2009, 
Saleeba et al. • Biophysical Models and Survey

Efficiency

Kearney et al. 2010, Dormann et al. 2012, Guillera-Arroita 2017, Mathewson et al. 2017). Clearly, however, an animal can only be active in the environment when its core body temperature is within physiologically tolerable limits (Porter et al. 1973). Outside of these limits, the animal is either dead, seriously impeded, or no longer active. As such, thermal constraints on activity provide a real, and forecastable constraint on detectability. Mechanistic niche modeling approaches target these constraints to identify times when an animal is unlikely to be present (Kearney and Porter 2009, Kearney et al. 2010).

Mechanistic niche models consider all the environmental factors (e.g., solar radiation, thermal radiation from sky and ground, conduction with the ground, convection from wind, air temperature, relative humidity) that determine the temperature of organisms and their habitats. Thus, they involve first modeling the microclimate and then using the microclimate predictions in organism-specific models of heat exchange to infer the presence-absence or behavior of an animal (Porter et al. 1973; Gates 1980; Kearney and Porter 2004, 2009, 2019). This generates a mechanistic understanding of how an animal's traits fundamentally limit their use of the environment. As such, mechanistic niche models provide an intrinsically safer base from which to forecast (Porter et al. 1973; Gates 1980; Kearney and Porter 2004, 2009; Kearney et al. 2010; Mathewson et al. 2017).

The primary strength of mechanistic niche models, however, is in identifying conditions, and hence places and times, outside the fundamental niche of an organism (Kearney 2019). Unless all possible constraining forces (e.g., resources, other species) 
Saleeba et al. • Biophysical Models and Survey

Efficiency

are included, these models will tend to over-predict when or where an individual can exist. Mechanistic niche models allow us to place sensible constraints on how an animal might behave under different weather conditions, and they allow us to generate these constraints at any time or place (Kearney and Porter 2004, 2009; Mathewson et al. 2017). The 3 modeling steps to generate constraints are predict the microclimate experienced by the animal, compute the body temperature for the target animal in this microclimate, and determine whether this temperature is within physiological and behavioral constraints of the organism (Porter et al. 1973, Kearney and Porter 2009). This strategy has been used for a wide range of purposes (including species distribution modeling; Kearney and Porter 2009), but it has yet to be applied to estimate detection probabilities for the purpose of survey design.

We used a biophysical model to place constraints on detection, and we used the striped legless lizard (Delma impar) as a case study. This species is restricted to lowland temperate grassland in south-eastern mainland Australia (Australasian Regional Association of Zoological Parks and Aquaria [ARAZPA] 1996, Maldonado et al. 2012, Howland et al. 2016). It is a diurnally active, egg-laying lizard that reproduces in spring and summer and reaches around $250 \mathrm{~mm}$ in length (ARAZPA 1996, Dorrough and Ash 1999, O’Shea 2005). The striped legless lizard is a nationally threatened species in Australia and is the focus of sustained ongoing monitoring effort.

The objective of this study was to develop a forecasting model of the detection probability of the striped legless lizard, a cryptic ectotherm. Our hypothesis was that a 
Saleeba et al. • Biophysical Models and Survey

Efficiency

mechanistic niche model, which takes into account the environmental fluxes and the physiological constraints of the subject organism, would enable optimal survey conditions to be forecast.

\section{STUDY AREA}

Field monitoring occurred 2016-2017 at Iramoo Wildflower Grassland Reserve, a 32ha grassland remnant on the Keilor Plains approximately $18 \mathrm{~km}$ west of Melbourne,

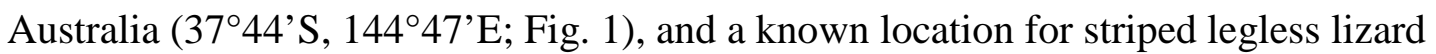
(at relatively high abundance). This locality has a temperate, seasonal climate with mean monthly maximum air temperatures peaking at $26.7^{\circ} \mathrm{C}$ in February and mean monthly minima reaching $5.5^{\circ} \mathrm{C}$ in July (Bureau of Meteorology, station 086282). Winter is June-August, and Summer is December-February. The site is relatively flat, with an elevation of $60 \mathrm{~m}$ above sea level. It is dominated by kangaroo grass (Themeda triandra) and introduced needle grasses (Nassella spp.) and is part of the community Natural Temperate Grasslands of the Victorian Volcanic Plain.

\section{METHODS}

Striped legless lizards are monitored by placing artificial shelters (roofing tiles) in arrays in the animal's habitat and systematically searching beneath these cover objects. We parameterized a biophysical model to predict the microclimate underneath these tiles and used this, in combination with the measured thermal limits and preferences of the species, to predict when the lizard may be under the tiles. We assessed the biophysical predictions against an intensive 12-month monitoring effort. 
Saleeba et al. • Biophysical Models and Survey

Efficiency

We also used the monitoring data to fit a (statistical) occupancy model that estimated detection probability as a function of temperature and season.

\section{Field Monitoring}

To estimate observed detection and how it varies with temperature and season, we conducted fortnightly (i.e., every 2 weeks) surveys at Iramoo Wildflower Grassland Reserve from June 2016-May 2017. We surveyed 8 grids, each of 50 concrete tiles with the tiles spaced $5 \mathrm{~m}$ apart in a $5 \times 10$ arrangement. Tiles were $43.5 \times 34 \times 1 \mathrm{~cm}$ in size. In each survey, we recorded the presence or absence of striped legless lizards under each tile. The species also shelters under vegetation, and in soil cracks, where we would not detect them using our tile surveys. We used an infrared thermometer (T420; FLIR Systems, Wilsonville, OR, USA) to record the temperature of the tile's under-surface and the substrate under the tile. Because of the low dispersal ability of striped legless lizards (O’Shea 2005, Maldonado et al. 2012), we treated each grid as having independent populations.

We focused on temperature as the primary variable influencing detection of the striped legless lizard. Many factors, biotic and abiotic, affect the distribution and activity of the lizard, but temperature is particularly important given we focused on an ectotherm. Temperature is also convenient because it is a variable that can be readily forecast and incorporated into explicit biophysical models of heat transfer. Thus, in the statistical and biophysical model, we included temperature as our primary abiotic variable affecting detection.

This article is protected by copyright. All rights reserved. 
Saleeba et al. • Biophysical Models and Survey

Efficiency

We conducted this study in accordance with the Australian code for the care and use of animals for scientific purposes. Approval for field observations and laboratory tests was granted by the University of Melbourne Animals Ethics Committee (project number 1513714).

\section{Analysis}

To estimate observed occupancy and detection probability, we used a binomial mixture model (Royle 2004, Oppel et al. 2014), fitting the model using JAGS through the rjags package (Plummer 2016) within R (R Core Team 2017). For each tile, we assumed that the observed presence of a lizard $\left(P_{o b s}\right)$ was drawn from a Bernoulli distribution with some probability $\left(p_{i, t}\right)$ of an individual being present under a tile at that site and time. This presence of individuals is a function of occupancy at each site $\left(O_{i}\right)$, which is assumed constant through time at each site, and the detection probability $\left(p_{d e t, t}\right)$, which varies through time as a function of season and observed temperatures.

$$
P_{o b s} \sim \operatorname{Bernoulli}\left(p_{i, t}\right),
$$

where $p_{i, t}=O_{i} \times p_{\text {det }, t}$, and $O_{i} \sim \operatorname{Bernoulli}\left(p_{o c c, i}\right)$.

The expected occupancy and detection probabilities were a function of covariates using linear models with a logit-link. For the probability of occupancy $\left(p_{o c c, i}\right)$, the predictor variable was site, which is represented by the different tile grids, $i$. 
Saleeba et al. • Biophysical Models and Survey

Efficiency

$$
\operatorname{logit}\left(p_{o c c, i}\right)=\alpha_{i}
$$

where $\alpha_{i}$ is the log odds of the occupancy for each tile grid.

The detection model had 2 temperature predictor variables: substrate temperature under the tile $\left(T_{s u b}\right)$ and the difference in temperature between the tile's under-surface and the substrate $\left(T_{\text {diff }}\right)$. We also included a first-order Fourier function to capture annual cycling in detection:

$$
\begin{aligned}
\operatorname{logit}\left(p_{\text {det }, t}\right)= & \beta_{1} T_{\text {sub }}+\beta_{2}\left(T_{\text {sub }}\right)^{2}+\beta_{3} T_{\text {diff }}+\beta_{4}\left(T_{\text {diff }}\right)^{2} \\
& +\beta_{5} \text { sine }(\text { day of year })+\beta_{6} \text { cosine }(\text { day of year })+\text { intercept }
\end{aligned}
$$

We included the squared term for the temperature variables because there should be a band of preferred $T_{\text {sub }}$ and $T_{\text {diff }}$, and this is captured in a quadratic response. For the season predictor variable, we transformed day of the year on which the survey was conducted into radians (day of year $\times \frac{2 \pi}{365}$ ).

We used minimally informative priors (Table S1, available online in Supporting Information), and ran 3 Markov chains for 30,000 iterations, discarding the first 20,000 iterations as a burn-in. We then thinned the samples by 5 . We assessed model convergence using trace plots and the Gelman-Ruben diagnostic test (Toft et al. 2007), which indicated convergence for all parameters.

Predicting the under-tile microclimate.-For the mechanistic modeling (Fig. 2), we used the biophysical modeling package NicheMapR version 1.3 (Kearney and Porter 2017), a coupled microclimate and animal heat-and-mass-balance model run

This article is protected by copyright. All rights reserved. 
Saleeba et al. • Biophysical Models and Survey

Efficiency

within R (R Core Team 2017); NicheMapR has previously been described in Kearney and Porter (2017, 2019) and Kearney et al. (2019). We present parameters used for the model and an example script to simulate ectotherm presence using survey tiles (Table S2 and Appendix S1, available online in Supporting Information).

To predict the temperature of the tile's under-surface and of the substrate under the tile (i.e., the tile and substrate layers, respectively), we adapted the microclimate and ectotherm models to represent these layers (Fig. 2). For parameterization of the microclimate model, we modified a calibrated microclimate model, adjusting parameter settings for solar reflectance, wind speed, and the organic cap layer present on the soil surface (Table S3, available online in Supporting Information). The model was forced by gridded daily weather data as described in Kearney et al. (2014) and Kearney and Maino (2018; see details on microclimate model calibration, available online in Supporting Information). From this microclimate model, the substrate could be represented by the 1-cm-deep soil layer, which approximately corresponds to the thickness of the tile siting above this substrate layer. We then used the ectotherm model to simulate heat exchange for a tile. We used the output of the microclimate model as an input for this tile ectotherm model, but we substituted the 1-cm-deep soil layer as the surface microclimate layer for the tile (to account for the shading effect of the tile). We then ran the ectotherm model to represent a tile lying flat on the ground by setting the ectotherm model to simulate an inanimate object with the geometry of a plate and by using the tiles' properties (Table S2). We weighed and measured the tiles to obtain their mass and dimensions, respectively, and calculated the density using the water-displacement 
Saleeba et al. • Biophysical Models and Survey

Efficiency

method. We measured the solar reflectance using a dual spectrometer system (Ocean Optics, Dunedin, FL, USA; Smith et al. 2016). To analyze the accuracy of these tile and substrate layers, we compared their predicted temperatures against observed measures using the root mean squared error. We did this for 2 different tile types: concrete and terracotta. We ran a sensitivity analysis to see how sensitive the tile model was to different environmental factors (see details on sensitivity analysis, available online in Supporting Information).

Thermal physiology of striped legless lizards.-The above model generated hourly estimates of temperature in the target microclimate (i.e., under a roofing tile lying on the ground). We then required information on the behavioral and physiological limits of our target species. We sourced 10 individual striped legless lizards for this study from a captive population held by Zoos Victoria. These comprised wild-caught adult lizards brought to Melbourne Zoo in 2012-2013, and several of their offspring (which had matured). At the zoo they were housed in a communal enclosure $(120 \times 73 \times 73 \mathrm{~cm})$ layered with $5 \mathrm{~cm}$ of blue metal rock at the bottom for drainage, then $15 \mathrm{~cm}$ of palm peat and $3 \mathrm{~cm}$ of palm fiber on top. The enclosure had 2 grass tussocks planted in the center and 5 refuges (terracotta tile fragments) laid between the palm peat and fiber. Over spring and summer, the lizards were fed 3 times a week with 10 small crickets/lizard. At the University of Melbourne, striped legless lizards were housed individually in plastic cages $(30 \times 17.5$ $\times 9.5 \mathrm{~cm}$ ). The cage's base had $2.5 \mathrm{~cm}$ of palm peat. A refuge, inverted plant pot with a hole in the side as an entrance and exit, was at either end of the cage. Palm fiber filled the remaining cage space. They were housed in a room kept at $21-22{ }^{\circ} \mathrm{C}$ and in 
Saleeba et al. • Biophysical Models and Survey

Efficiency

racks that provided a temperature gradient of $21-32{ }^{\circ} \mathrm{C}$ across the cages during the day and a constant $21^{\circ} \mathrm{C}$ at night. The lizards were fed 5 crickets/week and had their enclosures sprayed with water twice/week. All lizards had complete tails.

We measured the preferred temperature $\left(T_{p r e f}\right)$ as the mean of all body temperature measurements for an individual, voluntary thermal minimum $\left(V T_{\min }\right)$ as the minimum of all body temperature measurements for an individual, and voluntary thermal maximum $\left(V T_{\max }\right)$ as the maximum of all body temperature measurements for an individual using the laboratory thermal gradient described in Kearney and Predavec (2000). These behavioral parameters define, respectively, the temperature the organism will preferably target and the minimum and maximum temperature the organism will voluntary tolerate before seeking lower or higher body temperatures. The temperature-controlled room cycled between $15^{\circ} \mathrm{C}$ (night) and $23^{\circ} \mathrm{C}$ (day) with humidity maintained at $40 \%$. The room's lights were on a 12 -hour light-dark photocycle and the gradient's heat lamps at the hot end were on from 0900-1700. The lizards were in the gradient for 24 hours, with the first 1.5 hours to acclimate. We recorded body temperatures every 20 minutes using an infrared camera (FLIR-T420) from 1800-2230 and then 0700-1630 the following day. Because of the striped legless lizard's small size, the dorsal surface temperature is an accurate representation of internal body temperature. We used values only from daytime measurements.

To measure the critical thermal minimum temperature $\left(C T_{\min }\right.$; the temperature at which the lizard is no longer able to right itself), we first acclimated the lizards to room temperature $\left(21^{\circ} \mathrm{C}\right)$ for 1 hour and then placed them in an incubator and 
Saleeba et al. • Biophysical Models and Survey

Efficiency

acclimated them to $10{ }^{\circ} \mathrm{C}$ for 1 hour. We then transferred the lizards to a small ziplock bag, which we placed in a water bath. The temperature of the water bath started at $10{ }^{\circ} \mathrm{C}$ and we lowered it in increments of $0.5^{\circ} \mathrm{C}$ every minute. We briefly removed lizards from the water bath and gently prodded them to assess their ability to move normally. Once we reached a temperature where the lizard was unable to move, we maintained the temperature and checked the lizard for movement again. If the lizard did not make a normal movement again, we recorded the temperature of the water as the $C T_{\text {min }}$.

Ground-truthing the biophysical model.-To assess how well the biophysical model predicted microclimatic temperature, we measured the microclimate underneath roofing tiles, and below these into the soil. We did this using 2 grids of 16 tiles in a $4 \times 4$ arrangement spaced $5 \mathrm{~m}$ apart. Grid 1 was in an area with a mixture of native kangaroo grass and exotic tussock grasses (Nassella trichotoma and $N$. neesiana) that were not densely packed together. Grid 2 was in an area dominated by the 2 exotic tussock grasses and the vegetation was growing densely packed together. Each grid consisted of 8 concrete and 8 terracotta tiles, randomly dispersed in the grid. Each tile had 2 temperature data loggers (Thermochron iButtons, DS1922L, Maxim Integrated, San Jose, CA, USA): one placed on the tile's under-surface and one in the substrate under the tile. For both grids, we placed 2 poles with temperature data loggers placed at $0,2.5,5,10,30$, and $60 \mathrm{~cm}$ along their length in the ground to measure the soil temperature at these depths. We collected data from 1 June 2016-15 January 2017 when a fire burned the site.

This article is protected by copyright. All rights reserved. 
Saleeba et al. • Biophysical Models and Survey

Efficiency

Predicting times when striped legless lizards are likely not underneath roofing tiles.-To predict the striped legless lizard's possible presence under tiles, we used the ectotherm model to explicitly simulate their thermoregulatory behavior at each hour of the day. To simulate this behavior, the model places the animal either on the surface (in the open or shade) or in burrows underground (within a certain specified depth range). This behaviorally calibrated ectotherm model will move the animal deeper if it gets too cold (below the $C T_{\min }$ ) or too hot (higher than the mean of the $V T_{\max }$ and $\left.C T_{\max }\right)$. Then, for each hour of the day, the model checks for the correct photoperiod for activity (depending on if the animal is diurnal, nocturnal, or crepuscular). If the animal is above a certain threshold temperature for emergence, the model computes the temperature of the animal above ground and assesses if it is suitable for the animal to be either basking or actively moving around.

To obtain a prediction for when striped legless lizards might use tiles for protected basking, we ran a simulation using the behavioral module of the ectotherm model. For this simulation we created an hourly temperature variable, which was the mean of the tile and substrate temperature layers created above because the lizards would not be directly experiencing the tile or substrate temperature but a temperature in between. We then allowed the striped legless lizards to be active by giving them the option to be under the tile for protected basking, or to retreat to underground burrows. There is anecdotal evidence suggesting that striped legless lizards burrow down 1015 cm (M. B. O’Shea, Victoria University, personal observation), likely by using abandoned spider burrows; hence, in the model, the lizards were allowed to either be in a 10 -cm or 15-cm-deep burrow or under the tile. From this, we obtained predictions 
Saleeba et al. • Biophysical Models and Survey

Efficiency

of when striped legless lizards could be using the tiles for protected basking. To see when striped legless lizards could be surface active, we ran the behavioral ectotherm model using the original microclimate output without the tile and substrate layers and overlaid these predictions with striped legless lizards under the tile to infer times when they could only be under the tiles when on the surface. We then overlaid the observed presences and absences of striped legless lizards from the fortnightly surveys with the predictions of when they would be under concrete tiles and created a confusion matrix of true-false presences and absences to test the accuracy of the model's predictions.

A hybrid statistical-mechanistic model.-Finally, we fitted a statistical prediction model, in which we used the biophysical model plus season as predictors for detection probability, and we compared this model (in terms of deviance explained) to the original statistical model that used temperature variables to infer detection probability. The result was a hybrid model: a statistical model in which some of the inputs have a mechanistic underpinning.

\section{RESULTS}

\section{Observed Detection}

Over the course of the survey period, one observer (KS) flipped 10,027 tiles. Only 53 of these tile flips resulted in an observation of striped legless lizard resulting in 57 animals across 53 observations. We did not locate any striped legless lizards in 3 of our grids (1, 4, and 7) and we excluded these from further analysis. 
Saleeba et al. • Biophysical Models and Survey

Efficiency

Our statistical model explained around $26 \%$ of the null deviance. Season had a large effect on detection probability, with detection more likely in spring and early summer (Fig. 3; Table S4, available online in Supporting Information). Both the substrate temperature and temperature difference also influenced detection probability independent of underlying seasonal effects (Fig. 4).

Only the $T_{\text {diff }}$ parameter was unequivocally different from 0 (95\% CI $=0.20$ 1.12). But the $\left(T_{\text {sub }}\right)^{2}$ and $\left(T_{\text {diff }}\right)^{2}$ parameters gave a strong indication of being negative (95\% CI $=-0.65-0.03$ and 95\% CI $=-0.29-0.05$, respectively), suggesting an optimal value for detection along both of these axes, with only a $4.4 \%$ and $10.2 \%$ chance that $\left(T_{s u b}\right)^{2}$ and $\left(T_{\text {diff }}\right)^{2}$, respectively, were positive. Substrate temperatures from $20-35{ }^{\circ} \mathrm{C}$ (a range within the organism's voluntary thermal limits) had the highest probability of detection for striped legless lizards and substrate temperatures lower than $15^{\circ} \mathrm{C}$ and higher than $40^{\circ} \mathrm{C}$ (outside voluntary thermal limits) had very low chance of detection. The detection probability increased from a $5-25^{\circ} \mathrm{C}$ difference in temperature (Fig. 4), an effect presumably capturing the tile's value as a sheltered thermoregulation site.

\section{Microclimate and Thermal Physiology}

The concrete tiles reached higher maximum temperatures than did the terracotta tiles, and the model was able to capture the substrate and tile temperatures to within a root mean squared error of $1.3^{\circ} \mathrm{C}$ in June, which increased to $3.6^{\circ} \mathrm{C}$ in December. The predictive accuracy was greatest during winter (Jun-Aug), and lowest during summer (Dec-Feb), when the model under-predicted the amplitude of the daily fluctuations 
Saleeba et al. • Biophysical Models and Survey

Efficiency

(Fig. 5; Fig. S4, available online in Supporting Information). The model was able to produce a slightly better fit for the substrate compared to the tile (Table S5, available online in Supporting Information).

After excluding observations from when the lizards went to sleep at night until when they moved the next day (because the lizards were perceived as not regulating their body temperatures for activity during those hours), we found no seasonal shift in $V T_{\min }, V T_{\max }$, and $T_{\text {pref }}$ (bootstrapped $P>0.05$ ). Hence, we pooled the spring and summer data to compute the thermal physiology parameters used in the model (Table S6, available online in Supporting Information). The mean $C T_{\min }$ measured was 4.15 ${ }^{\circ} \mathrm{C}\left(95 \% \mathrm{CI}=3.89-4.41^{\circ} \mathrm{C}\right)$.

\section{Predicting Presence and Detection}

Across the whole year from June 2016-May 2017, there were times during the day when the conditions under the tile were thermally suitable for striped legless lizards to use them as a retreat site and as a protected basking site (Fig. 6A). There were times in the middle of the day from spring to autumn where it was too hot under the tile during the daytime, and times during the night and early morning where the tile was too cold during winter. The terracotta tile had fewer hours and days when the tile was too hot for striped legless lizards to occupy, compared to concrete tiles.

When we assumed that striped legless lizards only use tiles for protected basking and then used 10- or 15-cm-deep burrows as retreat sites, the time periods for when we might detect them under the tile decreased (Fig. 6B). This protected basking simulation suggested that, from June 2016-May 2017, striped legless lizards could 
Saleeba et al. • Biophysical Models and Survey

Efficiency

have been found under tiles across the year except for mid-winter. From early- to mid-spring, they were predicted to be under the tiles throughout the day. From midspring to early-autumn, striped legless lizards were only predicted to use the tiles in the early morning and late afternoon. The terracotta tiles provided more hours and days for tile usage over the warmer months and fewer over the colder months compared to concrete tiles. For all of the times striped legless lizards can be detected under the tiles, they also had the potential to be surface active. Of the 23 survey hours where striped legless lizards were found under concrete tiles, the behavioral model predicted 18 of these correctly (5 incorrectly; Fig. 6B). Of the 87 hours when lizards were not observed, the model predicted lizards to be present in 46 of those hours.

Finally, we integrated the biophysical model predictions to develop the hybrid, semi-mechanistic model, and compared its fit to the survey data in comparison with that of the purely statistical model using deviance statistics. The statistical model (reported above) explained approximately 26\% of the null deviance (a deviance of 454.4 for 14 parameters); the semi-mechanistic detection model explained approximately 25\% of the null deviance (a deviance of 459.9 for 11 parameters). Because parameters are not entirely independent, formal model comparison requires an estimate of the effective number of parameters for each model, but this statistic is not currently estimable for this class of model. Nonetheless, it is clear that the semimechanistic model explains a very similar amount of the null deviance compared with the temperature model, and it does so with fewer nominal parameters. The fact that the hybrid model predicts detection as a function of a mechanistic prediction (a binary

This article is protected by copyright. All rights reserved. 
Saleeba et al. • Biophysical Models and Survey

Efficiency

yes or no) means that it should be a priori a safer model to extrapolate into new areas and climates.

\section{DISCUSSION}

Field ecologists typically design survey effort around times and places when they expect their target species to be present and detectable. These expectations are usually generated by the individual ecologist's experience and understanding of the organism, an often-powerful mental model that incorporates constraint (understanding of the organism) and correlation (observation and experience). Such a mental model is also implicit, poorly described, and tends to vary between individual ecologists. If we want predictions that are consistent and clear in their assumptions, formal models are preferable.

To date, most formal models of species detection are statistical in nature. These statistical models estimate relationships between survey-level variables (time, temperature, and so on), and the detection probability of the species. Since becoming readily available, statistical detection models have become widely used, and are now routinely employed for designing survey programs. Like all correlative models, however, these detection models are best used within the sampled environment space. Using correlative models to predict to new conditions (i.e., those in unsampled areas, or in the future) is, like all extrapolation, risky. This is particularly true when (as is typically the case) the statistical model incorporates no inherent constraints.

One obvious constraint experienced by most organisms is that of temperature on activity. It is now possible to compute these constraints mechanistically and in a 
Saleeba et al. • Biophysical Models and Survey

Efficiency

manner highly specific to a species and its habitat, but this had not been attempted prior to our study. In our case study we have considered a cryptic, threatened lizard species that is surveyed in the context of checking artificial retreat sites.

Our biophysical model did a satisfactory job of estimating temperatures in the target microclimate, roofing tiles arrayed on the ground, and when combined with measured behavioral and physiological limits, it allowed us to identify constraints: times and places where striped legless lizards were unlikely to be detected. The microclimate model takes as input gridded daily weather data available at the continental scale (5-km resolution; Kearney and Maino 2018), rather than on-site weather measurements; thus, there is scope to make similar predictions of tile temperatures at other sites within the species’ range.

In our 12-month, fortnightly monitoring surveys, we detected lizards in only 23 hours of our survey, and only 5 of these detection-hours (22\%) were at times our model identified as a priori unlikely. Our model did, however, predict many hours as suitable, though our surveys revealed no sign of the lizards (Fig. 6). This overprediction is expected given that the strength of mechanistic models is in identifying the unsuitable conditions, the conditions where the organism is likely absent (Kearney et al. 2010). We examined only temperature as a constraint; if we added other constraining variables, such as water availability or the presence of other species, the predicted number of unsuitable time intervals (Fig. 6) would increase with each additional constraint. This limitation in the mechanistic model's predictions explains why the model predicts lizard presences in late summer and autumn, times when 
Saleeba et al. • Biophysical Models and Survey

Efficiency

lizards are, in fact, almost never observed. Clearly some unaccounted factor other than temperature explains the absence of the lizards at this time.

The statistical model captures the phenomenon as a seasonal trend in detection but gives us very little insight into what the cause might be (Kearney and Porter 2009, Mathewson et al. 2017). Many possibilities are present. For example, the substrate develops deep soil cracks over the summer, and these cracks close up again during the wet winter when the clay expands. Waudby and Petit (2017) reported that soil cracks provide a more stable microclimate (in terms of temp and humidity) compared to surface retreat sites. Other studies have suggested that striped legless lizards do use soil cracks for shelter (Osmond 1994, O’Shea 2005) and that there is an association between the striped legless lizard's occupancy of grassland sites and those sites having cracking-clay soils (Dorrough and Ash 1999). Thus, the seasonal availability of cracks as an alternative shelter (or as a rapid retreat when tiles are lifted) likely explains the notable lack of animals in autumn, and this constraint is not included in our model.

The other fundamental reason for over-prediction by the mechanistic model is that it is deterministic and takes no heed of the observation process (Kearney and Porter 2009, Kearney et al. 2010, Mathewson et al. 2017). The statistical detection model reveals that the detection probability for this species is low; even when animals are present and conditions are good, there is still a very good chance they are not observed. Thus, the mechanistic model over-predicts for both reasons of design and nature, and much of the over-prediction is unsurprising when low detection 
Saleeba et al. • Biophysical Models and Survey

Efficiency

probability is taken into account. Perhaps of more interest are the 5 (of 23)

observations of lizards where the mechanistic model suggested they should not be present. Each of these 5 observations was a single lizard seen within the hour (as opposed to the other 18 hours in which typically $>1$ lizard was seen) and all occurred when the tiles were predicted to be too hot. Thus, many of these apparent misclassifications by the model might simply be animals moving transiently beneath a tile as the observer approached. Alternatively, they may reflect true bias in the model's parameterization, potentially because, for simplicity, we assumed mean values for measured parameters. For example, we set the voluntary thermal maximum $\left(V T_{\text {max }}\right)$ in our model to $34.5^{\circ} \mathrm{C}$, which was the mean value for this parameter, so around half of the lizards chose to be at temperatures higher than $34.5^{\circ} \mathrm{C}$ (highest maximum recorded was $41.33^{\circ} \mathrm{C}$ ). There are also some hints in the data that parameters vary seasonally; measured striped legless lizards preferred significantly cooler temperatures over spring compared to summer (M. R. Kearney, University of Melbourne, unpublished data). There is clearly population variation in our key parameters, and by ignoring it we risk inaccurate predictions.

The statistical model revealed a generally low detection probability, a strong seasonal trend in detection, and a strong role for temperature in detection of lizards under tiles. We structured temperature into our linear model in a nuanced way, allowing quadratic responses to temperature and to the difference between substrate and tile temperature. This allows the model to capture a range of temperature variables optimal for detection, and the model did this quite effectively (Fig. 4). Statistical models are, however, implicit in the processes that they capture (Kearney 
Saleeba et al. • Biophysical Models and Survey

Efficiency

and Porter 2009, Kearney et al. 2010, Dormann et al. 2012, Guillera-Arroita 2017, Mathewson et al. 2017) and there is no guarantee that relationships unearthed in one sample will apply to another population. Thus, prediction beyond the sampled population is dangerous; particularly as our models become more complex. By swapping the raw temperature variables (temp, temp difference, and squared temp) out of the model and replacing them with the binary prediction from the biophysical model, we incorporated a real, quantified constraint into our statistical model (Mathewson et al. 2017). We incorporated the constraint as a variable rather than a fundamental part of the model's structure, but doing so is nonetheless an improvement over a model with no particular constraint. When we did this, it was encouraging to observe the single categorical variable from the biophysical model effectively played the same role as all the temperature variables in the previous model. This is evidenced by the similar amount of deviance explained but also by the similar estimates for the seasonal effect in both models. We would expect the biophysical model to explicitly capture the optimal values in the temperature variables, and it appears to have done this.

\section{MANAGEMENT IMPLICATIONS}

Using biophysical models, we can design evidence-based survey regimes designed to avoid wasted effort surveying at times and places where detection is impossible or unlikely. Many field ecologists would argue that they already make such decisions without a model using their experience and understanding of the organism's basic biology. Such an argument misses the fact that an ecologist's experience and learning

This article is protected by copyright. All rights reserved. 
Saleeba et al. • Biophysical Models and Survey

Efficiency

generates a model, one that is no doubt powerful, but also idiosyncratic. Formally defined models are a way of reducing these uncertainties, and when such models are rooted in fundamental biophysical constraint, they can be used to forecast into conditions with which we have no experience (such as those under climate change or at an entirely new location). Where repeat survey data are available, we can use biophysical forecasts as inputs into statistical detection models, allowing us to develop survey designs that account for fundamental organismal constraints. The cost of incorporating these constraints is relatively minor for temperature constraints. Seasonal weather data for computing microclimates are available for any part of the world stretching back to the 1950s and the only additional requirement is information on the thermal preferences and limits of the particular species, information that is often already available or easily estimable (in the worst case, based on related taxa). The biophysical modeling script associated with this paper can be easily adjusted to suit other ectotherms and so allow managers to produce constraint predictions for other ectotherms in other times and places.

\section{ACKNOWLEDGMENTS}

We thank C. Banks, J. Birkett, and Zoos Victoria for allowing access to their captive population of striped legless lizard, the Cairnlea Conservation Reserves Committee of Management for allowing use of to use Iramoo Wildflower Grassland Reserve, and R. Aguliar and K. Rankin for technical support.

This article is protected by copyright. All rights reserved. 
Saleeba et al. • Biophysical Models and Survey

Efficiency

\section{LITERATURE CITED}

Australasian Regional Association of Zoological Parks and Aquaria [ARAZPA]. 1996. Populations and habitat viability assessment (PHVA) for the striped legless lizard (Delma impar). Australian Capital Territory Parks and Conservation, Striped Legless Lizard Working Group, Australasian Regional Association of Zoological Parks and Aquaria (ARAZPA), Conservation Breeding Specialist Group (SSC/IUCN), Canberra, Australia.

Barr, J. M., and A. M. Wilson. 2015. A feasibility study of using unmanned aerial vehicles to survey avian abundance by using audio recording. Annual Conference Mid-Atlantic Chapter Ecological Society of America. Elizabethtown College, 17-19 April 2015, Elizabethtown, Pennsylvania, USA.

Dormann, C. F., S. J. Schymanski, J. Cabral, I. Chuine, C. Graham, F. Hartig, M. Kearney, M. Xavier, C. Römermann, B. Schröder, and A. Singer. 2012. Correlation and process in species distribution models; bridging a dichotomy. Journal of Biogeoragphy 39:2119-2131.

Dorrough, J. W., and J. E. Ash. 1999. Using past and present habitat to predict the current distribution and abundance of a rare cryptic lizard, Delma impar (Pygopodidae). Australian Journal of Ecology 24:614-624.

Downs, C. T., C. Greaver, and R. Taylor. 2008. Body temperature and basking behaviour of Nile crocodiles (Crocodylus niloticus) during winter. Journal of Thermal Biology 33:185-192.

This article is protected by copyright. All rights reserved. 
Saleeba et al. • Biophysical Models and Survey

Efficiency

Gates, D. M. 1980. Biophysical ecology. Springer-Verlag, New York, New York, USA.

Geiger, R. 1950. The climate near the ground. Harvard University Press, Cambridge, Massachusetts, USA.

Gompper, M. E., R. W. Kays, J. C. Ray, S. D. Lapoint, D. A. Bogan, and J. R. Cryan. 2006. A comparison of noninvasive techniques to survey carnivore communities in northeastern North America. Wildlife Society Bulletin $34: 1142-1151$

Guillera-Arroita, G. 2017. Modelling of species distributions, range dynamics and communities under imperfect detection: advances, challenges and opportunities. Ecography 39:281-295.

Hodapp, D., I. Westbrooke, M. Lettink, J. Hoare, and C. O’Donnell. 2009. Optimising the sampling of skinks using artificial retreats based on weather conditions and time of day. Applied Herpetology 6:379-390.

Howland, B. W., D. Stojanovic, I. J. Gordon, D. Fletcher, M. Snape, I. A. Stirnemann, and D. B. Lindenmayer. 2016. Habitat preference of the striped legless lizard: implications of grazing by native herbivores and livestock for conservation of grassland biota. Austral Ecology 41:455-464.

Huey, R. B., C. R. Peterson, S. J. Arnold, and W. P. Porter. 1989. Hot rocks and notso-hot rocks: retreat-site selection by garter snakes and its thermal consequences. Ecology 70:931-944.

This article is protected by copyright. All rights reserved. 
Saleeba et al. • Biophysical Models and Survey

Efficiency

Kearney, M. R. 2019. The fundamental niche concept connects individuals to populations: a comment on Angilletta et al. Integrative and Comparative Biology 59:1509-1510.

Kearney, M. R., P. K. Gillingham, I. Bramer, J. P. Duffy, and I. M. D. Maclean. 2019. A method for computing hourly, historical, terrain-corrected microclimate anywhere on Earth. Methods in Ecology and Evolution 11:38-43.

Kearney, M. R., and J. L. Maino. 2018. Can next-generation soil data products improve soil moisture modelling at the continental scale? An assessment using a new microclimate package for the R programming environment. Journal of Hydrology 561:662-673.

Kearney, M., and W. P. Porter. 2004. Mapping the fundamental niche: physiology, climate, and the distribution of a nocturnal lizard. Ecology 85:3119-3131.

Kearney, M., and W. P. Porter. 2009. Mechanistic niche modelling: combining physiological and spatial data to predict species’ ranges. Ecology Letters $12: 334-350$.

Kearney, M., and W. P. Porter. 2017. NicheMapR - an R package for biophysical modelling: the microclimate model. Ecography 40:664-674.

Kearney, M., and W. P. Porter. 2019. NicheMapR - an R package for biophysical modelling: the ectotherm and Dynamic Energy Budget models. Ecography 42:1-12.

This article is protected by copyright. All rights reserved. 
Saleeba et al. • Biophysical Models and Survey

Efficiency

Kearney, M., and M. Predavec. 2000. Do nocturnal ectotherms thermoregulate? A study of the temperate gecko Christinus marmoratus. Ecology 81:2984-2996.

Kearney, M. R., A. Shamakhy, R. Tingley, D. J. Karoly, A. A. Hoffmann, P. R. Briggs, and W. P. Porter. 2014. Microclimate modelling at macro scales: a test of a general microclimate model integrated with gridded continental-scale soil and weather data. Methods in Ecology and Evolution 5:273-286.

Kearney, M. R., B. A. Wintle, and W. P. Porter. 2010. Correlative and mechanistic models of species distribution provide congruent forecasts under climate change. Conservation Letters 3:203-213.

Maldonado, S. P., J. Melville, G. N. L. Peterson, and J. Sumner. 2012. Humaninduced versus historical habitat shifts: identifying the processes that shaped the genetic structure of the threatened grassland legless lizard, Delma impar. Conservation Genetics 13:1329-1342.

Mathewson, P. D., L. Moyer-Horner, E. A. Beever, N. J. Briscoe, M. Kearney, J. M. Yahn, and W. P. Porter. 2017. Mechanistic variables can enhance predictive models of endotherm distributions: the American pika under current, past, and future climates. Global Change Biology 23:1048-1064.

McGrath, T., G. Guillera-Arroita, J. J. Lahoz-Monfort, W. Osborne, D. Hunter, and S. D. Sarre. 2015. Accounting for detectability when surveying for rare or declining reptiles: turning rocks to find the grassland earless dragon in Australia. Biological Conservation 182:53-62.

Michael, D. R., R. B. Cunningham, C. F. Donnelly, and D. B. Lindenmayer. 2012. Comparative use of active searches and artificial refuges to survey reptiles in temperate eucalypt woodlands. Wildlife Research 39:149-162.

This article is protected by copyright. All rights reserved. 
Saleeba et al. • Biophysical Models and Survey

Efficiency

Oppel, S., P. Marczakiewicz, L. Lachmann, and G. Grzywaczewski. 2014. Improving aquatic warbler population assessments by accounting for imperfect detection. PLoS One 9:1-7.

O’Shea, M. B. 2005. Methods for assessment and techniques for management of striped legless lizard Delma impar populations in south-eastern Australia. Dissertation, Victoria University of Technology, Victoria, Australia.

Osmond, H. 1994. Habitat specialisation and the isolation of remnant populations of the striped legless lizard, Delma impar (Pygopodidae). Report to ACT Parks and Conservation Service. Australian National University, Canberra, Australian Capital Territory, Australia.

Plummer, M. 2016. rjags: Bayesian graphical models using MCMC. R Package version 4.6. < https://cran.r-project.org/web/packages/rjags/index.html>. Accessed 20 May 2018.

Porter, W. P., J. W. Mitchell, W. A. Beckman, and C. B. DeWitt. 1973. Behavioral implications of mechanistic ecology: thermal and behavioral modeling of desert ectotherms and their micrioenvironment. Oecologia 13:1-54.

R Core Team. 2017. R: a language and environment for statistical computing. R Foundation for Statistical Computing, Vienna, Austria.

Royle, J. A. 2004. N-mixture models for estimating population size from spatially replicated counts. Biometrics 60:108-115.

This article is protected by copyright. All rights reserved. 
Saleeba et al. • Biophysical Models and Survey

Efficiency

Smith, K. R., V. Cadena, J. A. Endler, M. R. Kearney, W. R. Porter, and D. StuartFox. 2016. Color change for thermoregulation versus camouflage in freeranging lizards. American Naturalist 188:668-678.

Toft, N., G. T. Innocent, G. Gettinby, and S. W. J. Reid. 2007. Assessing the convergence of Markov chain Monte Carlo methods: an example from evaluation of diagnostic tests in absence of a gold standard. Preventive Veterinary Medicine 79:244-256.

Tracy, C. R., S. J. Reynolds, L. McArthur, C. R. Tracy, and K. A. Christian. 2007. Ecology of aestivation in a cocoon-forming frog, Cyclorana australis (Hylidae). Copeia 2007:901-912.

Waudby, H. P., and, S. Petit. 2017. Thermoregulatory value of cracking-clay soil shelters for small vertebrates during extreme desert conditions. Integrative Zoology 12:237-249.

Associate Editor: Sarah Baker.

\section{Figure legends.}

Figure 1. The field site, Iramoo Wildflower Grassland Reserve, Australia. The top of the map is north. Marked in white are the 8 survey grids where we collected the presence-absence data on striped legless lizards and the corresponding temperature data discussed, June 2016-May 2017. In red are the 2 additional grids where we used temperature data loggers to collect continuous temperature data underneath the 
Saleeba et al. • Biophysical Models and Survey

Efficiency

roofing tiles and also at different soil depths. Data source is Google Earth (Google,

Mountain View, CA, USA), August 2017.

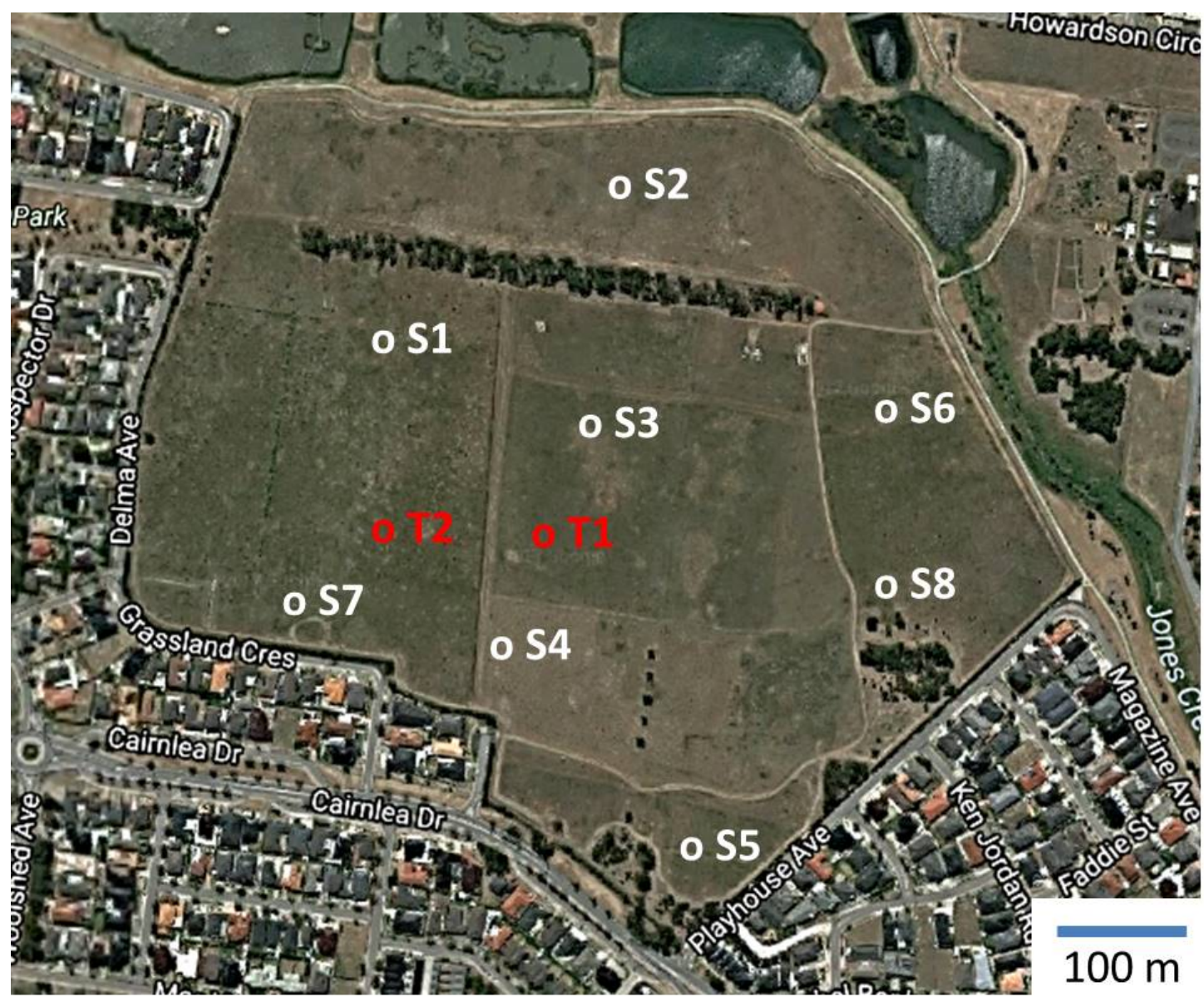

This article is protected by copyright. All rights reserved. 
Saleeba et al. • Biophysical Models and Survey Efficiency

Figure 2. Outline of the mechanistic modeling process used to model the thermal microclimate underneath roofing tiles and to model when striped legless lizards might use roofing tiles for protected basking at Iramoo Wildflower Grassland Reserve, Australia, 2016-2017.

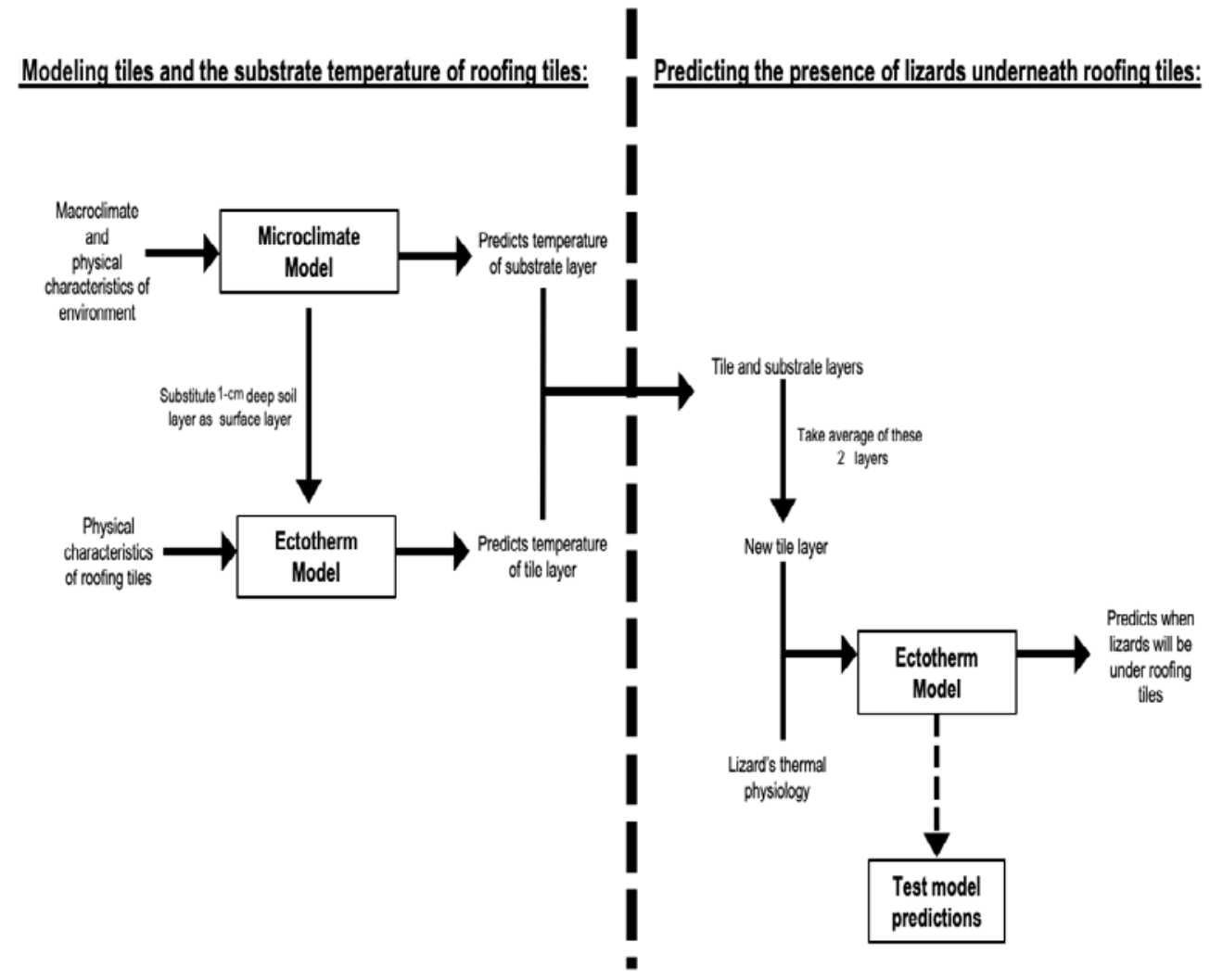

This article is protected by copyright. All rights reserved. 
Saleeba et al. • Biophysical Models and Survey Efficiency

Figure 3. The seasonal effects on detection probability (black line) and the observed proportion of striped legless lizards present (gray dots) under the roofing tiles at Iramoo Wildflower Grassland Reserve, Australia, 2016-2017. Error bars represent the standard error for the proportion present. Day 0 corresponds to 1 January. For plotting the effect of season on the detection probability, we set the 2 temperature predictor variables to their mean values (which was 0 because the variables were scaled).

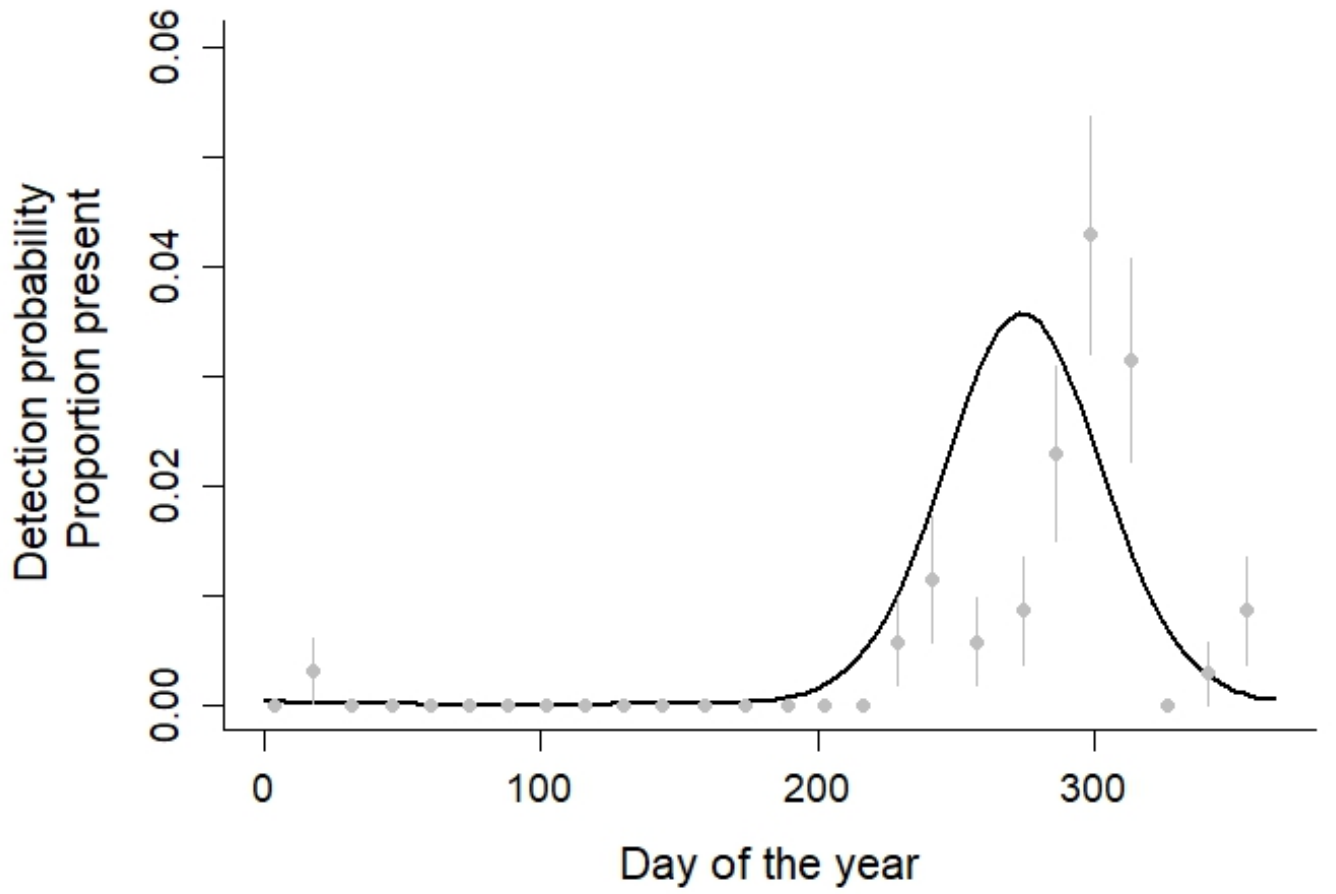

This article is protected by copyright. All rights reserved. 
Saleeba et al. • Biophysical Models and Survey

Efficiency

Figure 4. Combined effects of substrate temperature and temperature difference (the difference in temperature between the under-surface of the roofing tile and the substrate) on the detection probability (black lines) at Iramoo Wildflower Grassland Reserve, Australia, 2016-2107. The observed presences (red circles) and absences (transparent grey circles) of striped legless lizards in the field for these 2 temperature predictor variables are shown. As the intensity of the grey circles increases, the number of absence records for those temperature conditions increases. For plotting the effect that the 2 temperature predictor variables had on the detection probability, we set the day of the year to 275, which is the ordinal day where maximum probability of detection occurred.

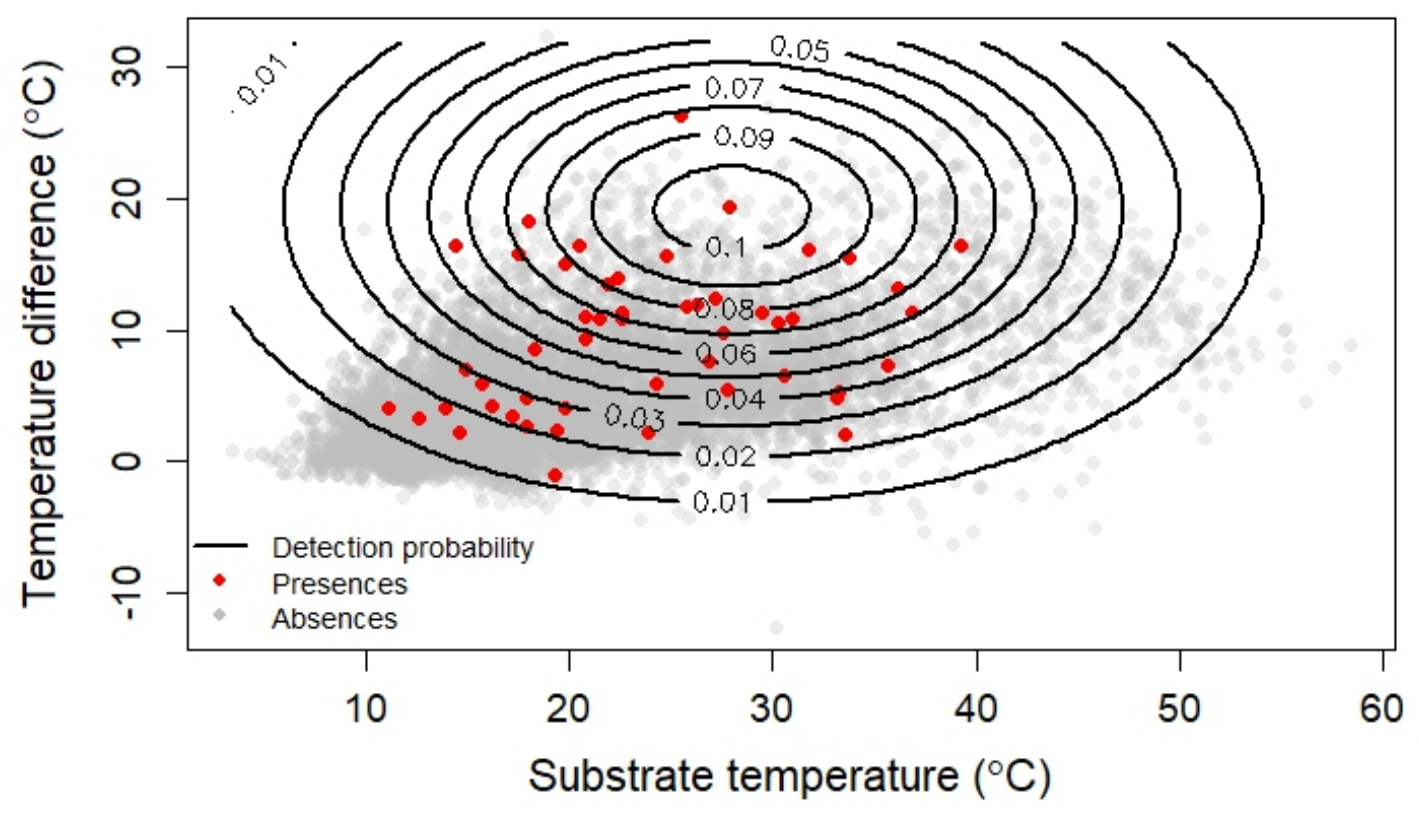

This article is protected by copyright. All rights reserved. 
Saleeba et al. • Biophysical Models and Survey Efficiency

Figure 5. Hourly predictions (black) and observations (red) of the tile's temperatures for concrete (left panel) and terracotta (right panel) roofing tiles for Grid 1 at Iramoo Wildflower Grassland Reserve, Australia, for a fortnight (8-22) in June, September, and December in 2016. Other dates, and Grid 2 had similar root-mean-squared-errors but are not shown because fine-scale deviations between model and data are not discernible when data are plotted at full scale.
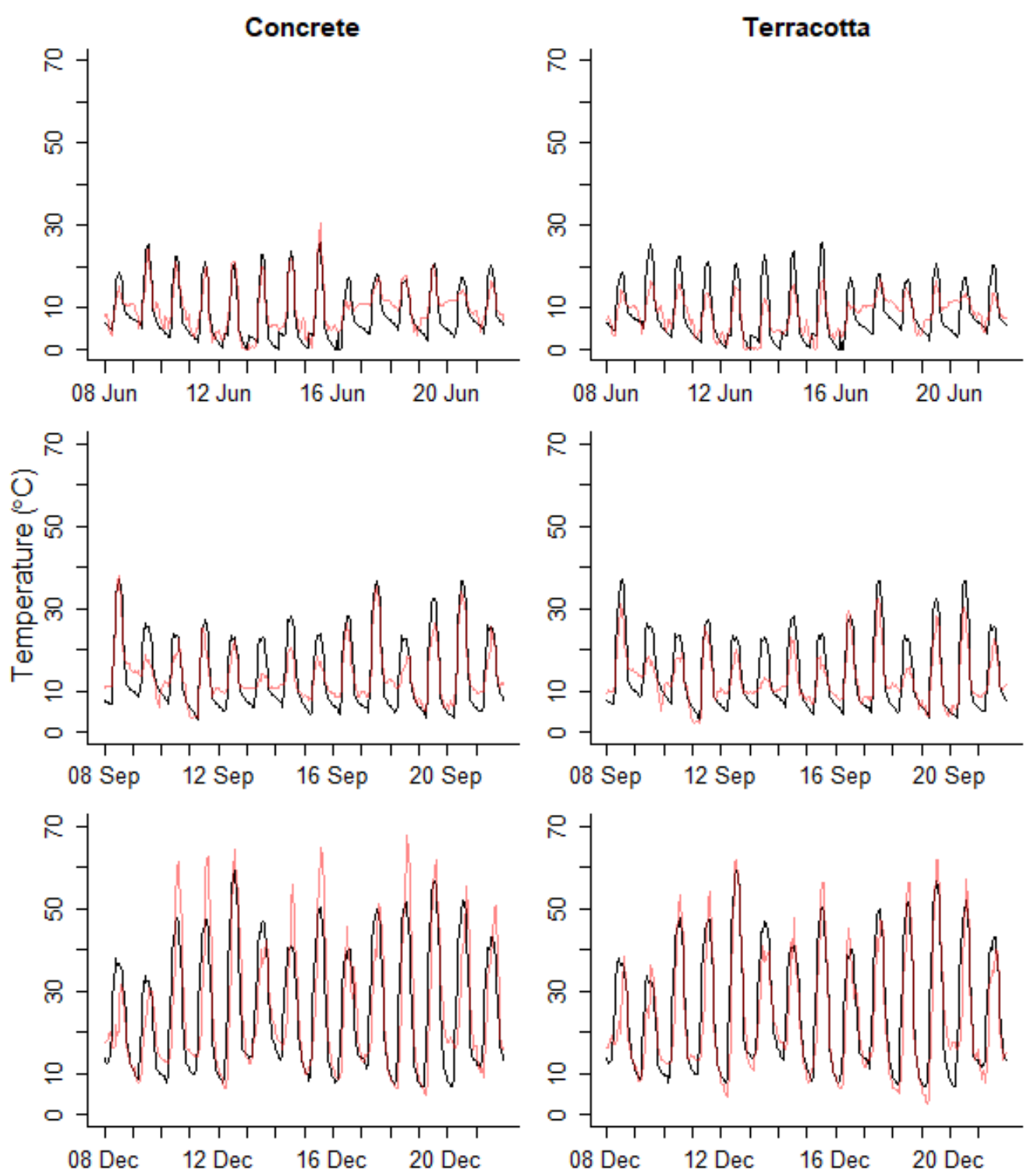

This article is protected by copyright. All rights reserved. 
Saleeba et al. • Biophysical Models and Survey Efficiency
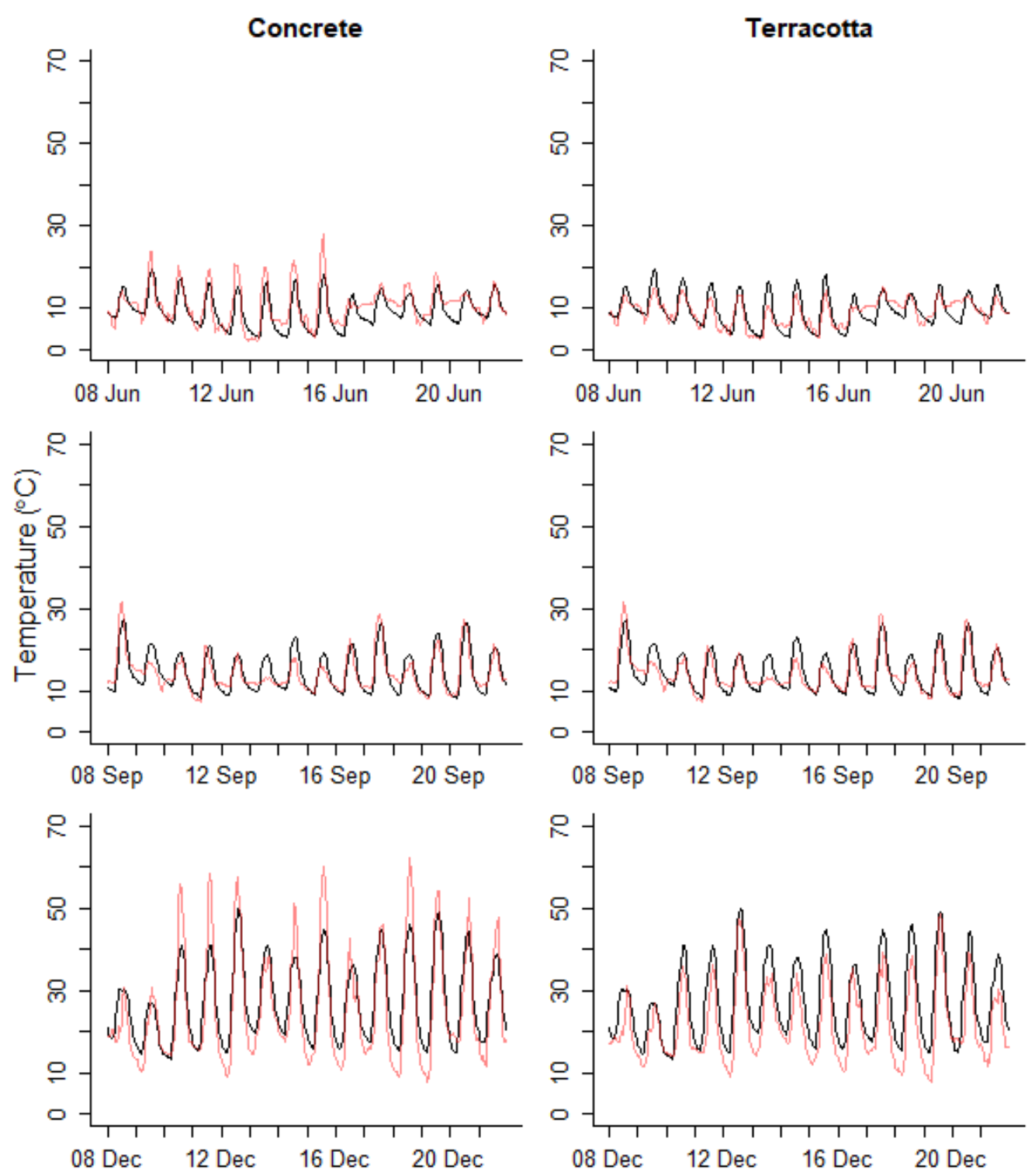

This article is protected by copyright. All rights reserved. 
Saleeba et al. • Biophysical Models and Survey

Efficiency

Figure 6. The predictions from the behavioral model's simulations for striped legless lizards from June 2016-May 2017 for concrete roofing tiles (i) and terracotta roofing tiles (ii) at Iramoo Wildflower Grassland Reserve, Australia. A) The thermal suitability of the roofing tile. Red shows when the roofing tile is thermally suitable, and grey (daytime hours) and blue (nighttime hours) show when it is too hot or too cold for striped legless lizards to be under the roofing tiles. B) The predictions when striped legless lizards could have used roofing tiles for protected basking. Orange shows the times that the striped legless lizards are predicted to be able to use the roofing tiles for protected basking. Grey represents the hours in the day when the roofing tiles are predicted to be either too hot or too cold for striped legless lizards to be using the roofing tiles for protected basking. Blue are the nighttime hours. For frame B(i) The observed presences $(\bullet)$ and absences $(\bullet$ ) of striped legless lizards in the field under concrete roofing tiles are overlaid on top of the predictions. For all of the times striped legless lizards can be detected under the roofing tiles, they also had the potential to be surface active outside of the roofing tiles.

This article is protected by copyright. All rights reserved. 
Saleeba et al. • Biophysical Models and Survey Efficiency
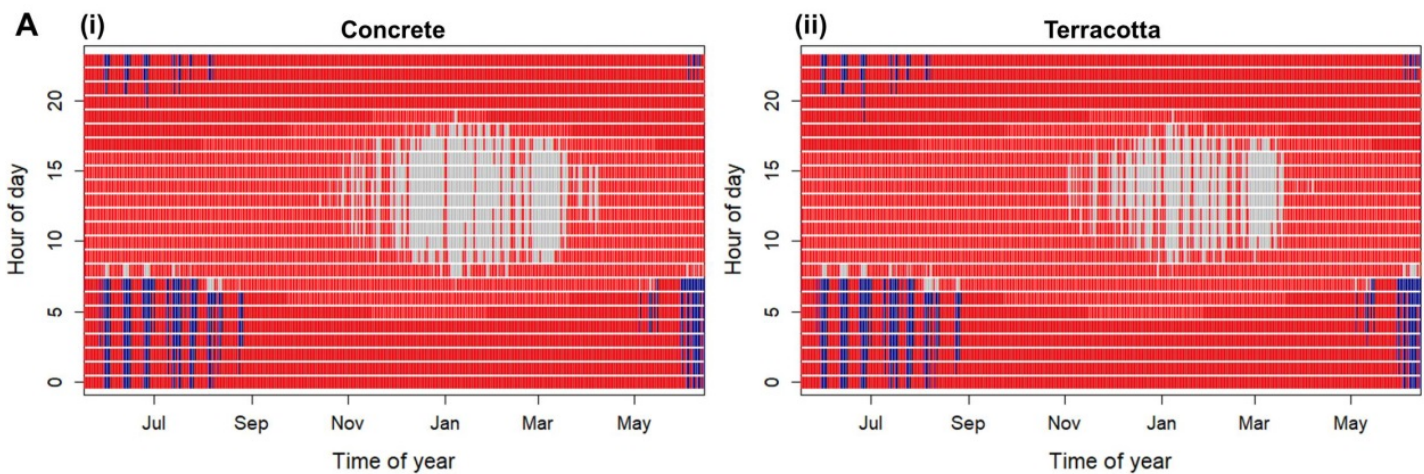

B (i)

(ii)
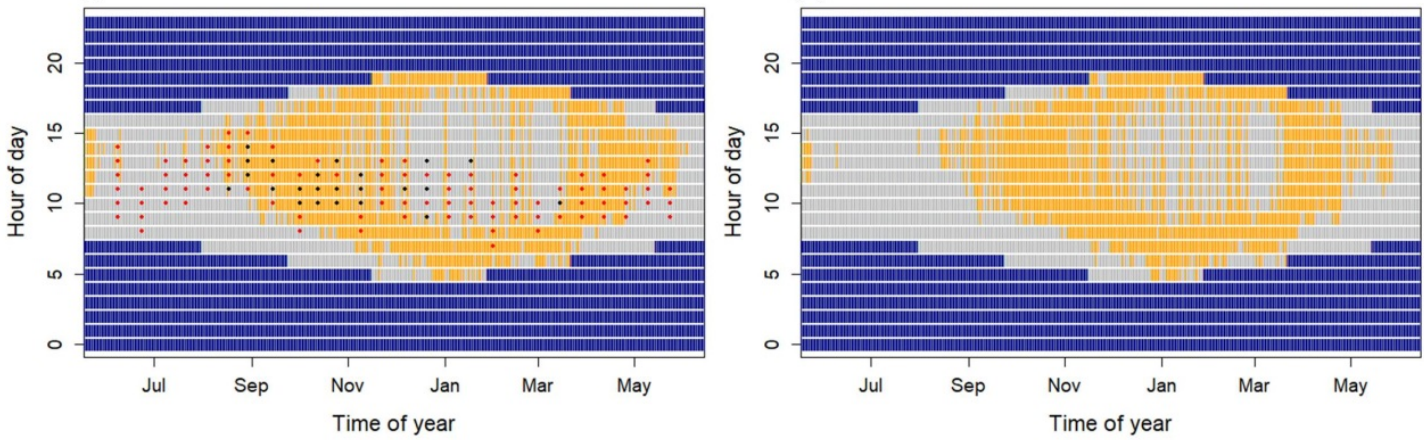

\section{Summary for online table of content}

We compare biophysical and statistical detection models using data on a threatened

legless lizard. We show that using biophysical predictions as inputs to the statistical model generates robust forecasts of detection probability.

This article is protected by copyright. All rights reserved. 


\section{University Library}

\section{- M M N E R VA A gateway to Melbourne's research publications}

Minerva Access is the Institutional Repository of The University of Melbourne

Author/s:

Saleeba, K;Phillips, BL;O'Shea, M;Kearney, MR

Title:

Using Biophysical Models to Improve Survey Efficiency for Cryptic Ectotherms

Date:

2020-06-13

Citation:

Saleeba, K., Phillips, B. L., O'Shea, M. \& Kearney, M. R. (2020). Using Biophysical Models to Improve Survey Efficiency for Cryptic Ectotherms. JOURNAL OF WILDLIFE MANAGEMENT, 84 (6), pp.1185-1195. https://doi.org/10.1002/jwmg.21890.

Persistent Link:

http://hdl.handle.net/11343/275903 